\title{
The Importance of Early Diagnosis and Treatment in Hidradenitis Suppurativa:
}

\section{Case Report and Literature Review}

\author{
Monica Shah ${ }^{1}$, Muskaan Sachdeva ${ }^{1}$, and Afsaneh Alavi ${ }^{2,3,4 *}$ \\ ${ }^{1}$ Faculty of Medicine, University of Toronto, Toronto, ON, Canada \\ ${ }^{2}$ York Dermatology Clinic and Research Centre, Richmond Hill, ON, Canada \\ ${ }^{3}$ Division of Dermatology, Women's College Hospital, Toronto, ON, Canada \\ ${ }^{4}$ Department of Medicine, University of Toronto, Toronto, ON, Canada
}

*Corresponding author: Alavi A, York Dermatology Clinic and Research Centre, Richmond Hill, ON, Canada, Email: afsaneh.alavi@utoronto.ca

Received: 05 May, 2020 | Accepted: 19 May, 2020 | Published: 26 May, 2020

Citation: Shah M, Sachdeva M, Alavi A (2020) The Importance of Early Diagnosis and Treatment in Hidradenitis Suppurativa: Case Report and Literature Review. J Clin Cosmet Dermatol 4(2): dx.doi.org/10.16966/2576-2826.151

Copyright: ( 2020 Shah M, et al. This is an open-access article distributed under the terms of the Creative Commons Attribution License, which permits unrestricted use, distribution, and reproduction in any medium, provided the original author and source are credited.

\section{Introduction}

Hidradenitis Suppurativa (HS) is a chronic inflammatory condition causing nodules, abscesses and sinus tracts to form in intertriginous areas, such as the axillae and buttocks [1]. Without prompt detection and management, HS can progress to debilitating end-stage disease [1]. Decreased Quality Of Life (QoL), poor self-image, interference with work/leisure activities, and comorbid mental illness may become devastating due to substantial pain, pruritis, scarring and malodorous purulent discharge [1-4]. With no confirmatory diagnostic tests, HS is diagnosed clinically; however, physicians' unfamiliarity with HS and its indistinctive early signs often lead to incorrect and delayed diagnoses $[3,5,6]$. HS is primarily managed with antibiotics and surgery; however, their efficacy often diminishes with increasing disease severity [6]. Late-stage disease is challenging to treat due to poor coordination between healthcare providers, limited awareness, and multiple comorbidities [7]. Thus, increased HS awareness is essential for early diagnosis and improved outcomes. Herein, we report a case of HS where prior misdiagnoses resulted in reduced QoL and a 5-year diagnostic delay, as well as review the literature.

Keywords: Hidradenitis Suppurativa; Early diagnosis; Timely management; Multidisciplinary approach; Improved patient outcomes

\section{Case}

A 43-year-old male presented with a 15-year history of recurrent painful inflammatory nodules, abscesses, and draining sinuses of the sacrum and buttocks (Figure 1). While the patient had been diagnosed with HS at our dermatology clinic five years ago, over the span of a decade prior to his eventual diagnosis, the patient undertook frequent visits to the emergency room, walk-in clinics, and primary care physicians. The patient had no family history of HS, no comorbidities, and did not take any medications that may have worsened the severity of his disease. His disease negatively affected his work productivity, sports, and his social and sexual relationships. $\mathrm{He}$ admitted feeling tremendously embarrassed and self-conscious and had consequently become more socially isolated from friends and family. His disease severity progressed to Hurley stage III as his condition remained undiagnosed. The patient underwent surgery in 2004 to treat a pilonidal sinus, received multiple incision and drainage for flares, and eventually received adalimumab $40 \mathrm{mg}$ weekly injections (HS dose) since 2017. As the diagnosis of Pilonidal Sinus Disease (PSD) occurred before our first contact with the patient, it is unclear whether the patient experienced newly localized PSD or HS. Despite treatment, by April 2019 the patient presented with limited improvements. The patient received ertapenem 1 gr daily as a bridge to surgery and subsequently underwent surgical excision of damaged tissue. With persisting discharge and pain noted during his last assessment in October 2019, further surgery is ultimately necessary to attempt to reduce inflammation and tissue injury.

\section{Discussion}

In our patient, self-inflicted social isolation, embarrassment, and impaired activities stemming from HS, led to a decrease in his QoL. HS patients often experience stigma, worsened QoL and impaired work productivity greater than other dermatological conditions, including atopic dermatitis and psoriasis [8]. In comparison to psoriasis, over a 3-year period a higher proportion of HS patients visited the emergency department [1]. Given the high comorbidity rates of HS with various physical and psychological disorders, as well as its overall disease complexity, multidisciplinary treatment should be approached early to ensure long-term relief and the avoidance of unnecessary healthcare resource expenditures [6].

Long diagnostic delays may stem in part from avoidance of disclosure to a General Practitioner (GP). Clerc H, et al. [3] found that 42 patients $(21.8 \%)$ considered their disease shameful, resulting in challenges consulting their GP. Further, Revuz JE, et al. [8] demonstrated that less than $50 \%$ of patients consulted for HS in a 1 -year period. This may be explained by the fact that lesions often spread to intimate areas and are accompanied by malodourous 


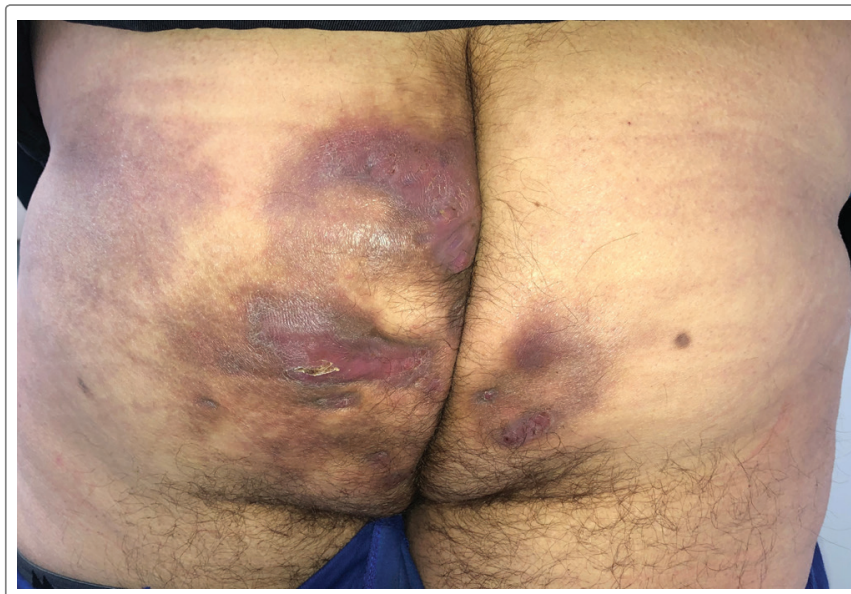

Figure 1: HS plaques of the buttocks at initial presentation.

Table 1: Common mimics of Hidradenitis suppurativa.

\begin{tabular}{|c|l|}
\hline Skin Diseases & $\begin{array}{l}\text { Acne Conglobata, Cystic Acne, Pilonidal Sinus, } \\
\text { Carbuncle/Furuncle, Furunculosis, Sebaceous Cyst, } \\
\text { Chronic Pyoderma Gangrenosum }\end{array}$ \\
\hline Skin Infections & $\begin{array}{l}\text { Bacterial Folliculitis, Boil, Cellulitis, Perianal Abscess, } \\
\text { Infected Bartholin Cyst, Erysipelas, Lymphadenitis, } \\
\text { Lymphogranuloma Venereum, Granuloma Inguinale, } \\
\text { Tuberculosis cutis, Tularemia, Actinomycosis, } \\
\text { Nocardiosis, Catscratch Disease }\end{array}$ \\
\hline Other & $\begin{array}{l}\text { Skin manifestations of Crohn's Disease, } \\
\text { Anal Fistula }\end{array}$ \\
\hline
\end{tabular}

discharge, causing embarrassment and subsequent hesitation to request help. Moreover, when symptoms are tolerable, patients are less likely to seek medical care [9]. Thus, it is common for their conditions to reach a severe state before treatment is sought. Collectively, reluctance to seek medical attention combined with inability to recognize the importance of treating tolerable symptoms early, may lead to delayed diagnosis [10].

Further, due to varying clinical presentations, HS is often mistaken for a simple infection, boil or other common mimics (Table 1) $[6,7,11$ 13]. In addition, some of these conditions may also be associated with HS, including pilonidal cyst disease, Crohn's disease, Graves' disease, Sjogren's syndrome, irritable bowel syndrome, arthritis, and acne conglobata [13]. Likely due to physician unfamiliarity with HS, our patient presentation left primary care physicians puzzled; he was previously thought to have a methicillin-resistant staphylococcus aureus infection. As a result, long diagnostic delays are common. Loget J, et al. [9] demonstrated that 170 (54\%), 114 (37\%) and 45 (15\%) patients had previously consulted 3, 5, and 10 different GPs respectively, before a formal diagnosis was made by a dermatologist (64\% of cases) [9]. This may also be attributed to limited HS exposure within curriculum taught to training physicians, resulting in a general lack of physician knowledge regarding the disease [3]. Failure to recognize HS can lead to unneeded treatment for incorrect diagnoses [14]. Overall, the average reported time between symptom onset and diagnosis of all included studies within our literature review was 6.4 years (Table 2) [4,7,9,11-21]. To avoid negative outcomes, early diagnosis and proper care for those suffering from HS are essential [22]. HS may be clinically diagnosed by the presence of 3 criteria: 1 .
Table 2: Reported cases of diagnostic delay in Hidradenitis suppurativa.

\begin{tabular}{|c|c|c|c|}
\hline Study & $\begin{array}{l}\text { Age at disease } \\
\text { onset (mean/ } \\
\text { median years) }\end{array}$ & $\begin{array}{c}\text { Age at } \\
\text { diagnosis } \\
\text { (mean/median } \\
\text { years) }\end{array}$ & $\begin{array}{c}\text { Delay in } \\
\text { diagnosis } \\
\text { (mean/median } \\
\text { years) }\end{array}$ \\
\hline Zimman S, et al. [4] & NR & 37 & 1.19 \\
\hline Lee EY, et al. [7] & $\begin{array}{l}\text { Second and } \\
\text { third decades } \\
\text { of life }\end{array}$ & NR & 12 \\
\hline Loget J, et al. [9] & 22 & 30.4 & 8.4 \\
\hline Nnamonu MI [11] & $\begin{array}{l}\text { After puberty } \\
\text { and before } \\
\text { age } 40\end{array}$ & NR & NR \\
\hline Beshara MA [12] & $11-50$ & NR & NR \\
\hline Williams ST, et al. [13] & 36 & NR & NR \\
\hline Saunte DM, et al. [14] & 24.7 & 31.9 & 7.1 \\
\hline Micheletti RG, [15] & 27.3 & 30.6 & 3.3 \\
\hline Kirsten N, et al. [16] & NR & NR & 4 \\
\hline Steele CE, et al. [17] & Early $20 \mathrm{~s}$ & NR & NR \\
\hline $\begin{array}{l}\text { Molina-Leyva A, et al. } \\
{[18]}\end{array}$ & 21 & NR & NR \\
\hline Mortimer PS, et al. [19] & 23.3 & NR & NR \\
\hline $\begin{array}{l}\text { Andrade TCPC, et al. } \\
{[20]}\end{array}$ & NR & $10-67$ & 9 \\
\hline Nassan $\mathrm{H}$, et al. [21] & 16.7 & 24.5 & NR \\
\hline
\end{tabular}

Abbreviations: NR=Not Reported

typical lesions (e.g. nodules, abscesses, sinus tracts, and scarring), 2. in typical locations (e.g. the axillae, inframammary folds, groin, and perineum), and 3. with more than 2 relapses in 6 months [7]. HS treatment may range from antibiotics, to invasive surgical procedures which may only provide temporary symptomatic relief [23]. In the case of our patient, only mild improvements were experienced; his condition worsened to Hurley stage III with continuous drainage and flaring. Stage III is characterized by extensive interconnected tracts, scarring, numerous lesions and pain, and is comparatively more challenging to manage than stage I [24]. Whereas in stage I treatment may halt disease progression [25] treatment of more severe cases often require a combination of intense lifestyle modifications, various pharmacologic therapies, and invasive surgeries, many of which are not curative and may be ineffective unless used early and aggressively [26]. Studies in the literature have demonstrated profound and severe impacts of a delayed HS diagnosis including reduced quality of life, financial consequences resulting from lost workdays, and increased expenditures by the healthcare system to treat patients with advanced stages of HS [14]. While pharmacological therapies provided our patient some relief, he eventually required surgical consultation suggesting unsatisfactory improvement and poor prognosis. With earlier diagnosis, both the need for and extent of surgery would have been significantly reduced with better expected outcomes.

Overall, our reported case is not rare amongst individuals suffering with HS. HS is characterized by a long patient journey that results from lack of diagnosis, frequent misdiagnosis, and a challenging multidisciplinary therapeutic approach [6]. The adverse impacts of HS that may result from delayed diagnosis highlight the importance 
of timely recognition and intervention. To attempt to diagnose HS more quickly, we highlight that the presence of a recurrent boil or abscess in folded skin should raise a red flag for further investigation of HS. Additionally, a positive family history of HS or Irritable Bowel Disease (IBD) in individuals who present with folliculitis-type lesions should increase the consideration of an HS diagnosis [27]. Although the medical community has gained a deeper understanding of HS through increased research and emerging HS patient support groups aimed at bringing awareness to this disease [28], further efforts need to be made to prevent an HS misdiagnosis and subsequently ensure prompt management.

\section{Conclusion}

To avoid complications and symptom recurrence that may require invasive interventions, it is imperative for primary care providers to be aware of the typical presentation of HS, and to be able to differentiate this disease from similar conditions so that interventions may be implemented quickly. Health care professionals need to work together to raise awareness with the aims of both diagnosing HS at an earlier stage, and of managing appropriately to avoid complications and improve treatment outcomes.

\section{Acknowledgements}

None

\section{Informed Consent}

Verbal informed consent was obtained from the included patient.

\section{Ethics Statement}

This research was conducted ethically in accordance with the Helsinki Declaration of 1975, as revised in 1983. The details in the case report are anonymized and no identifying information (e.g. names, initials or hospital numbers) is reported.

\section{Funding Sources}

\section{None}

\section{Conflicts of Interest}

Ms. Monica Shah and Ms. Muskaan Sachdeva have no conflicts of interest to disclose. Dr. Afsaneh Alavi has consulted for AbbVie, Janssen, LEO, Galderma, Novartis, Infla Rx and Valeant, and is also an investigator for AbbVie, Novartis, Regeneron, Pfizer, BoehringerIngelheim, Glenmark, Merck Serono, Roche, Xoma, Infla Rx, UCB and Xenon. Alavi received a grant from AbbVie.

\section{References}

1. Jemec GB, Kimball AB (2015) Hidradenitis Suppurativa: epidemiology and scope of the problem. J Am Acad Dermatol 73: S4-S7.

2. Pavon Blanco A, Turner MA, Petrof G, Weinman J (2019) To what extent do disease severity and illness perceptions explain depression, anxiety and quality of life in Hidradenitis Suppurativa? Br J Dermatol 180: 338-345.

3. Clerc H, Tavernier E, Giraudeau B, Bourdais-Sallot A, Samimi M, et al. (2019) Understanding the long diagnostic delay for hidradenitis suppurativa: a national survey among French general practicioners. Eur J Dermatol 29: 97-99.

4. Zimman S, Comparatore MV, Vulcano AF, Absi ML, Mazzuoccolo LD (2019) Hidradenitis supparativa: estimated prevalence, clinical features, concomitant conditions, and diagnostic delay in a university teaching hospital in Buenos Aires, Argentina. Actas Dermosifiliogr 110: 297-302.
5. Zouboulis CC, Marmol VD, Mrowietz U, Prens EP, Tzellos T, et al. (2015) Hidradenitis suppurativa/Acne Inversa: Criteria for diagnosis, severity assessment, classification and disease evaluation. Dermatology 231: 184-190.

6. Slade DEM, Powell BW, Mortimer PS (2003) Hidradenitis suppurativa: pathogenesis and management. Br J Plast Surg 56: 451-461.

7. Lee EY, Alhusayen R, Lansang P, Shear N, Yeung J (2017) What is hidradenitis suppurativa? Can Fam Physician 63: 114-120.

8. Revuz JE, Canoui-Poitrine F, Wolkenstein P, Viallette C, Gabison G, et al. (2008) Prevalence and factors associated with hidradenitis suppurativa: results from two case control studies. J Am Acad Dermatol 59: 596-601.

9. Loget J, Saint-Martin C, Guillem P, Kanagaratnam L, Becherel PA, et al. (2018) Misdiagnosis of hidradenitis suppurativa continues to be a major issue. The R-ENS verneuil study. Ann Dermatol Venereol 145: 331-338.

10. McMillan K (2014) Hidradenitis suppurativa: number of diagnosed patients, demographic characteristics, and treatment patterns in the United States. Am J Epidemiol 179: 1477-1483.

11. Nnamonu MI (2011) Hidradenitis suppurativa- A case report. J West Afr Coll Surg 1: 60-69.

12. Beshara MA (2010) Hidradenitis suppurativa: A clinican's tool for early diagnosis and treatment. Adv Skin Wound Care 23: 328-332.

13. Williams ST, Busby RC, DeMuth RJ, Nelson H (1991) Perineal hidradenitis suppurativa: presentation of two unusual complications and a review. Ann Plast Surg 26: 456-462.

14. Saunte DM, Boer J, Stratigos A, Szepietowski JC, Hamzavi I, et al. (2015) Diagnostic delay in hidradenitis suppurativa is a global problem. Br J Dermatol 173: 1546-1549.

15. Micheletti RG (2014) Natural history, presentation, and diagnosis of hidradenitis suppurativa. Semin Cutan Med Surg 33: S51-S53.

16. Kirsten N, Petersen J, Hagenstrom K, Augustin M (2020) Epidemiology of hidradenitis suppurativa in Germany- An observational cohort study based on a multisource approach. J Eur Acad Dermatol Venereol 34: 174-179.

17. Steele CE, Morrell D, Evans M (2019) Metabolic syndrome and inflammatory skin conditions. Curr Opin Pediatr 31: 515-522.

18. Molina-Levya A, Cuenca-Barrales C (2019) Adolescent-onset hidradenitis suppurativa: prevalence, risk factors and disease features. Dermatology 235: 45-50.

19. Mortimer PS, Dawber RP, Gales MA, Moore RA (1986) Mediation of hidradenitis suppurativa by androgens. Br Med J (Clin Res Ed) 292: 245-248.

20. Andrade TCPC, Vieira BC, Oliveira AMN, Martins TY, Santiago TM, et al. (2017) Hidradenitis suppurativa: epidemiological study of cases diagnosed at a dermatological reference center in the city of Bauru, in the Brazilian southeast state of Sao Paolo, between 2005 and 2015. An Bras Dermatol 92: 196-199.

21. Naasan H, Affleck A (2015) Atypical hidradenitis suppurativa. Clin Exp Dermatol 40: 891-893.

22. Duran C, Baumeister A (2019) Recognition, diagnosis, and treatment of hidradenitis suppurativa. JAAPA 32: 36-42.

23. Rondags A, van Straalen KR, van Hasselt JR, Janse IC, Ardon CB, et al. (2019) Correlation of the refined hurley classification for hidradenitis suppurativa with patient-reported quality of life and objective disease severity assessment. Br J Dermatol 180: 1214-1220. 
24. Matusiak L, Jemec GB, Szepietowski JC (2019) Pharmacological development in hidradenitis suppurativa. Curr Opin Dermatol 46: 65-72.

25. Grimstad O, Tzellos T, Dufour DN, Bremnes O, Skoie IM, et al. (2019) Evaluation of medical and surgical treatments for Hidradenitis Suppurativa Using Real-Life Data From The Scandinavian Registry (HISREG). J Eur Acad Dermatol Venereol 33: 1164-1171.

26. Dahmen RA, Gkalpakiotis $S$, Mardesicova L, Arenberger $P$, Arenbergerova M (2019) Deroofing followed by thorough sinus tract excision: a modified surgical approach for hidradenitis suppurativa. J Dtsch Dermatol Ges 17: 698-702.

27. Napolitano $M$, Megna $M$, Timoshchuk EA, Patruno $C$, Balato $N$, et al. (2017) Hidradenitis suppurativa: from pathogenesis to diagnosis and treatment. Clin Cosmet Investig Dermatol 10: 105-115.

28. Butt M, Cotton C, Kirby JS (2019) Support group utilization and impact for patients with hidradenitis suppurativa. J Am Acad Dermatol. 